\title{
DYNAMIC-AND-SYSTEMIC PRINCIPLES OF SYNERGETICS IN FUNCTIONAL LINGUISTICS
}

\author{
Victoria L. Malakhova \\ Moscow State Institute of International Relations (University), \\ 76, Prospekt Vernadskogo, Moscow, 119454, Russia
}

\begin{abstract}
The article describes the specifics, principles and methods of synergetics as a promising area of modern research. Synergetics is presented by the author as a holistic integral paradigm used in many sciences which confirms its interdisciplinary and even universal nature. The object of this paradigm is the interaction of complex systems, and since the mere concept 'system' is widely used in many scientific fields, the relevance of synergetics is beyond doubt. The author describes the main characteristics of the structure and functioning of a system. The key concepts of synergetics and their explanation are also given.

Further, the article discusses the branches of linguistics which use principles of synergetics - linguosynergetics and functional linguosynergetics as its variety. Since the study of text and discourse and their parameters as complex systems is of particular interest to many linguists, linguosynergetics has become one of the demanded scientific paradigms in this area of research. The author points out the objectives and tasks of linguistic synergetics, and functional linguosynergetics in particular, their basic concepts, principles and methods. Attention is also paid to the functioning of linguistic means, as well as the formation and interpretation of meaning depending on certain discursive space.

The author comes to the conclusion that thanks to synergetics language can be studied from specific angles, and the application of its principles greatly contributes to the theory of the evolution of language. Linguosynergetics provides ample opportunities for describing language/text/discourse as a complex dynamic open system, and functional linguosynergetics, in turn, helps describe the features of its functioning and evolution.
\end{abstract}

Key Words: synergetics, linguistic synergetics, functional linguosynergetics, system, language, discourse, structure, functioning, evolution

For citation: Malakhova V.L. (2021). Dynamic-and-Systemic Principles of Synergetics in Functional Linguistics. Philology at MGIMO, 7(3), pp. 24-33. https://doi.org/10.24833/2410-2423-2021-3-27-2433 


\title{
ДИНАМИКО-СИСТЕМНЫЕ ПРИНЦИПЫ СИНЕРГЕТИКИ В ФУНКЦИОНАЛЬНОЙ ЛИНГВИСТИКЕ
}

\author{
В.Л. Малахова \\ Московский государственный институт международных отношений (университет) МИД России, \\ 119454, Россия, Москва, пр. Вернадского, 76
}

\begin{abstract}
Аннотация. B статье описываются особенности, приниипы и методы синергетики, являющейся перспективным направлением современных исследований. Синергетика представлена автором как иелостная интегральная парадигма, применяемая во многих науках, что подтверждает её междисииплинарность и даже универсальность. Актуальность данной парадигмы обусловливается тем, что она занимается изучением взаимодействия сложных систем, а понятие «система» широко используется во многих научных сферах. Автор описывает основные характеристики и особенности структуры и функиионирования системь. Приводятся ключевые понятия синергетики, даётся их пояснение.

Далее в статье рассматриваются направления лингвистики, в основу которых легли приниипь синергетики - лингвосинергетика и, как её разновидность, функииональная лингвосинергетика. Поскольку особый интерес для многих исследователей представляет изучение текста и дискурса, их параметров как сложных систем, лингвосинергетика стала одной из востребованных научных парадигм в данном направлении исследований. Автор описывает объекты и задачи лингвистической синергетики и в частности функииональной тингвосинергетики, их основные понятия, принципь и методы. Уделяется внимание описанию функицонирования языковых средств, а также формированию и интерпретаиии смысла в зависимости от определённого дискурсивного пространства.

Автор приходит к выводу о том, что синергетика способна предложить специфический взгляд на язык, а применение её приниипов позволяет внести вклад в теорию эволюиии языка. Лингвосинергетика предоставляет широкие возможности для описания языка/текста/дискурса как сложной динамической открытой системы, а функииональная лингвосинергетика, в свою очередь, позволяет описать особенности её функиионирования и эволюиии.
\end{abstract}

Ключевые слова: синергетика, лингвистическая синергетика, функииональная лингвосинергетика, система, язык, дискурс, структура, функиионирование, эволюиия

Для цитирования: В.Л. Малахова (2021). Динамико-системные принципы синергетики в функциональной лингвистике. Филологические науки в МГИМО. 7(3), С. 24-33. https://doi. org/10.24833/2410-2423-2021-3-24-33 


\section{1. Введение}

$\mathrm{H}$ а современном этапе развития лингвистической науки появляется множество теорий, дополняющих друг друга и предлагающих свою интерпретацию языковых явлений. Это представляется закономерным, поскольку, как подчёркивает Ф.М. Березин, «одна какаялибо, даже всеобъемлющая теория не может дать всеохватное описание языка» [2, с. 22]. Тем не менее, предпринимаются попытки создать такую целостную интегральную парадигму.

Многие лингвисты сходятся во мнении, что подобную концепцию можно разработать на основе синергетического подхода за счёт его связности, всеединства синтезируемых областей знания, эволюционного и холистического видения мира [1]; [8]; [14].

Мы снова наблюдаем интерес к понятию система - одному из центральных терминов синергетики, востребованность принципов и законов синергетики в других науках. Быстрое развитие технологий, множество научных открытий, появление новых дисциплин приводит к значительным изменениям понимания термина система и возможностей его использования в научных исследованиях. Исследования в сфере лингвистики не являются исключением.

Поскольку окружающая нас реальность воспринимается как динамический конгломерат систем - социальных, физических, химических, биологических и т.д., исследователи стремятся создать всеобъемлющий научный взгляд на мир, основанный на законах, общих как для органической, так и для неорганической природы, создать сложную системную парадигму. Благодаря этому были предложены новые научные теории со своими методами исследования, что впоследствии послужило основой для синергетики как единого подхода к изучению различных сложных систем.

Целью данной статьи является анализ наиболее важных достижений синергетики и актуальность их применения в лингвистике.

\section{2. Результаты и обсуждение}

\section{1. Синергетика, её исходные положения и принципы}

Термин синергетика был введён немецким физиком Г. Хакеном для обозначения научного направления, изучающего внешние и внутренние взаимодействия сложных систем - их возникновение, самоорганизацию, развитие, изменение [13]. Важным для описания поведения такой системы является понимание воздействий внешней среды, при которых система способна сохранять стабильность и функционирование. Степень сложности синергийной системы определяется не только большим количеством её частей, но и широким спектром связей между ними, а также их способностью устанавливать новые связи с элементами других систем.

Под «сложностью» системы, как правило, понимают взаимосвязанность и взаимодействие множества компонентов, частей и уровней системы, их последовательность и сложное поведение [4]. Описывая сложные системы, Р. Бишоп среди наиболее важных характеристик называет большое число компонентов, нарушение симметрии структуры, иерархичность, связность, целостность, сложность поведенческих траекторий и др. [10, с. 111-112].

Сложность системы проявляется также в её функционировании, поэтому анализ и описание требуют применения новых научных методов, подходов и ракурса. Успешное применение концепций и методов синергетического подхода к описанию биологических, физических, экономических, исторических, социальных, а также лингвистических явлений выявило сходство, если не универсальность, принципов эволюции сложных систем. В результате синергетика позволила создать широкий спектр междисциплинарных взаимосвязей и рассматривается как концептуально-методологическая основа для междисциплинарного синтеза знаний.

Методологическая особенность синергетики заключается в изучении процессов развития определённого единства как многоуровневой саморегулирующейся структуры. Синергетика обусловила целостное восприятие мира, в котором всё взаимосвязано и постоянно меняется. Она представляет реальность как систему открытую, постоянно меняющуюся, нелинейную и бесконечную в выборе альтернатив для дальнейшего развития. 
Ключевыми понятиями синергетики являются интеграция, синтез, взаимодействие, согласованность, открытость, нелинейность, неравновесность, динамика, эволюиия и т.д., используемые для описания различных сложных систем, включая язык.

Применение синергетических методов и принципов в новых областях исследований эффективно для понимания и описания саморазвития системы - её основных стадий и фазовых сдвигов, колебаний, зон бифуркации и других особенностей. Поскольку язык является открытой саморазвивающейся сложной системой, синергетический подход к изучению различных аспектов его структуры и функционирования не только возможен, но и представляется необходимым.

Далее рассмотрим некоторые направления лингвистики, в основу которых легли принципы синергетики.

\section{2. Лингвосинергетика: междисциплинарный подход к изучению языка через концепту-} альную систему и методы синергетики

Многомерная онтология языка позволяет использовать синергетическую методологию в различных исследованиях. На современном этапе лингвистическая синергетика включает в себя две основные ветви - синергетику языка и синергетику речи. Особый интерес для многих исследований в данном направлении представляет синергетика текста и дискурса, нацеленная на установление их параметров, которые позволяют такой сложной системе, как текст/дискурс, формировать пространственные характеристики, а также раскрывать принципы успешного общения и способы коммуникативного влияния на поведение человека.

Основная задача лингвосинергетики языка состоит в выявлении и описании его внутренней динамической структуры, объяснении механизмов его изменений, в том числе в точках бифуркации (ветвления пути развития), в ситуациях реструктуризации и реорганизации.

Синергетика языка тесно связана с историческим языкознанием. Она направлена на понимание основных этапов эволюции языка, в том числе появления языка, особенностей его нелинейного развития (то постепенного, то быстрого), согласованного поведения его компонентов и подсистем, влияния внешних факторов на структуру языка и т.д. Исследование языка в рамках синергетической парадигмы также предполагает описание его особенностей как открытой самоорганизующейся системы - изучение языковой системы в её динамическом равновесии (синхрония) и в состоянии фазового перехода, что вызывает качественные изменения в организации и функционировании языка (диахрония). Синхронический и диахронический подходы представляют собой две необходимые, взаимодополняющие, взаимосвязанные плоскости исследовательского процесса. Несомненно важно не только знать современное состояние и функционирование анализируемой системы, но и раскрыть её принципы организации, «поведение» на той или иной стадии развития, наметить тенденции и возможные пути эволюции.

Как мы видим, синергетика предлагает специфический взгляд на языковую систему; применение принципов синергетического анализа и синтеза позволяет внести вклад в теорию эволюции языка как сложной динамической открытой саморегулирующейся системы.

Равновесное состояние языковой системы достаточно полно описано в традиционной лингвистике; лингвосинергетическое исследование языка в точках изменения существенно дополняет языковедческую науку. Известно, что язык постоянно меняется; однако его различные уровни и подсистемы меняются с разной скоростью. Основная задача лингвистической синергетики состоит в выявлении, описании и объяснении характеристик и внутренней динамики языка и тех механизмов, благодаря которым язык, претерпевая некие модификации, остаётся способным выполнять свои коммуникативные функции в обществе.

Итак, с использованием принципов синергетики становятся возможным моделирование и интерпретация фазовых сдвигов языковой системы, а также проектирование вариантов её изменения в зависимости от разнонаправленных бифуркаций и множества потенциальных аттракторов (целей развития системы). Синергетический подход является по сути динамико-системным, так как изучает речевую деятельность как образование системное, но подвижное, эволюционирующее. 


\section{3. Основные понятия синергетики и лингвосинергетики}

Новый подход к изучению сложных открытых динамических систем подразумевает введение новой терминологии, а также пересмотр некоторых концепций и понятий. Ниже приведены основные понятия синергетики, которые применяются в синергетическом направлении языкознания.

Закрытая / открытая система. Система представляет собой совокупность иерархически организованных компонентов (элементы, части, подсистемы и т.д.) и их связей, имеющих пространственные и временные границы, существующих в определённой среде [3]; [4]; [7]. Взаимодействие системы в целом и её компонентов с внешней средой делает эту систему открытой. Функционирование открытой системы происходит при поступлении информации (энергии) из внешней среды. Напротив, закрытая система не взаимодействует с внешней средой, что рано или поздно ведёт к вырождению системы. Большинство «живых» систем (в том числе язык) являются открытыми.

Открытый характер системы языка проявляется в реагировании на изменения и отражении социальной, экономической, политической и культурной жизни общества, научно-технических достижений. Язык передаёт новые понятия, сохраняя их в своей лексической подсистеме. В условиях многонационального общества и глобальных процессов язык не может не меняться, но, как и любая другая система, он стремится к самосохранению. Чтобы сохранить свою форму и функционирование, система может допускать внутренние и внешние колебания, отклонения в динамике своих компонентов лишь в той степени, при которой, даже создавая некоторую хаотизацию (отклонение от исходных параметров системы), они все же сохраняют подчинённость компонентов целому.

Линейность / нелинейность. В парадигме стабильности и равновесия линейность представляет собой последовательность причин и следствий, отображаемых в пропорциональной и детерминированной реакции системы на внутренние сигналы и на внешнее воздействие [3]; [7]; [9]. Нелинейные системы периодически подвержены хаотизации и не всегда предсказуемы, так как их поведение не обусловлено конкретными начальными условиями и не может быть определено общепринятым математическим принципом «Если X .., то Y ...». Описание поведения таких систем требует множества разноплановых факторов.

Синергетическая парадигма фокусируется на нелинейности как на более важном принципе в оппозиции линейность : нелинейность. Понятие линейности связано с упорядоченностью составных компонентов системы, например, языковых элементов в речевой цепи. Нелинейность же создаёт более сложную реальность с точки зрения моделей поведения системы, а также предусматривает исследование асимметрии, регулярности и неравномерности. Можно сказать, что нелинейность является концептуальным ядром синергетической парадигмы, которая также называется парадигмой нелинейности [3, с. 48]. Нелинейность языковой системы зависит от особенностей и функций системы и от поведения каждого её компонента, причём кумулятивный эффект условно выражается в формуле синергизма: $2+2=5$. Это особенно ярко проявляется в речи, когда общее смысловое пространство речевого произведения превосходит простую сумму смыслов всех отдельных компонентов текста [7]; [9].

Самоорганизаиия. Последовательность этапов самоорганизации сложной системы составляет динамику данной системы, её эволюцию. В синергетике самоорганизация является одновременно процессом и результатом последовательного взаимодействия многочисленных компонентов и частей системы, направленных на регулирование внутренней структуры этой системы. Системы, которые подвергаются пространственно-временным и функциональным сдвигам в результате внутренних процессов без вмешательства извне, называются самоорганизующимися системами [13, с. 69].

Язык также является самоорганизующейся системой, которая изменяется и развивается в соответствии с универсальными принципами поведения сложной системы, разработанными в общей теории синергетики. Являясь многокомпонентной синергийной системой, язык характеризуется сложным поведением элементов, частей и подсистем.

Синергетическая парадигма выделяет микроскопический и макроскопический уровни описания системы. Микроскопический уровень включает исследование элементарных компонентов и их поведения в данной системе, в то время как макроскопический уровень представляет собой 
описание динамики всей системы в результате её взаимодействий с внешним миром. Макроскопическая структура системы может быть описана с помощью макроскопических переменных параметров порядка [13].

Параметры порядка представляют собой характеристики определённой сложной системы. Это те факторы системы, которые управляют поведением (упорядочивают) её компонентов. Изменения в шаблоне параметров могут сигнализировать о структурном изменении сложной системы и наоборот. В речевой деятельности параметрами порядка признаются функциональные связи дискурса, которые организуют речь как коммуникативное событие, направленное на достижение заданной коммуникативной цели (или целей) [7]; [8].

Флуктуации и бифуркации. Под флуктуацией понимается временное изменение системы или постоянное переключение из одной точки в другую, которое может вызвать определённое отклонение в динамике системы, включая даже потерю устойчивости. Колебания могут привести систему к критической точке, называемой бифуркацией - своеобразному ветвлению или соединению возможных режимов существования системы. Далее система подвергается локальным и глобальным изменениям. Под локальными подразумевают непрерывные изменения формы при постоянном варьировании какого-либо динамического параметра или параметров. Более сложные, глобальные, изменения включают фазовые переходы, критические точечные переходы, где изменения могут быть прерывистыми и многочисленными, в основном из-за одновременно возможных колебаний на многих уровнях общей системы. Пройдя точку бифуркации, система приходит к новому стабильному состоянию [3]; [7].

Аттрактор репрезентирует состояние, к которому стремится система в процессе своего развития, независимо от начальных условий, и которое представлено в виде точки или траектории в фазовом пространстве системы [17]. Такое устойчивое состояние определяется с помощью набора логических правил (положительных и отрицательных взаимодействий), регулирующих развитие информации в самоорганизующейся системе. По сути, аттрактор является конечной точкой эволюции системы $[11$, с. 300]. Применительно к речи аттрактором выступает коммуникативная цель говорящего/пишущего [7]; [8].

Фрактал. Данный термин был введен математиком Б. Мандельбротом для описания модели «самоподобия» на каждом уровне и/или в масштабе структурной организации сложной системы. Фрактал представляет собой фрагментированную форму, которая может быть разбита на части, каждая или почти каждая из которых является уменьшенной копией целого [5]. Самоподобие признаётся в качестве основной характеристики фракталов.

Языковая система также имеет фрактальный тип организации: элементы одного уровня языка являются строительным материалом для более сложных комбинаций другого уровня языка и, в свою очередь, служат основой для ещё более сложных конфигураций на следующем уровне организации и так далее. Следует отметить, что чем выше уровень комбинаций, тем шире диапазон возможных альтернатив.

\section{4. Основные характеристики и особенности системной функциональной лингвосинерге- тики}

Одним из направлений лингвосинергетики является функциональная лингвосинергетика, которая органично синтезировала синергетическую методологию и основы теории системно-функциональной лингвистики (Systemic Functional Linguistics, или SFL), разработанной научной школой M. Хэллидея. Целый ряд положений SFL имеет существенное значение для функциональной лингвосинергетики.

Системно-функциональная лингвистика ставит своей целью изучение условий и процессов активизации тех или иных характеристик языка/речи/дискурса в зависимости от определённой коммуникативной ситуации в реальных условиях вербального взаимодействия [12, с. 143]; [15], [16]. Она рассматривает функционирование языка как ресурс, создающий смысл и взаимосвязь формы и значения и стремится соединить структурную (системную) информацию с экстралингвистическими факторами в интегрированное описание. Языковая система не является автоном- 
ной и независимой от внешних факторов, а, напротив, определяется ими. Как считают функционалисты, «именно в языке и слове оформляется концептуальный образ мира» [6, с. 35]. Такое понимание ведёт к поиску ответов на вопросы о том, какова цель (замысел) говорящего/пишущего; какие языковые средства являются наиболее оптимальными в достижении этой цели; какие именно факторы определяют выбор того или иного языкового средства и т.п. Таким образом, SFL - это теория, полностью основанная на понятии функциональности языка и с этих позиций объясняющая синтаксическую структуру языка. Язык рассматривается в действии, с учётом конкретной ситуации общения и понимается как речемыслительный инструмент, реализующий экстралингвистические цели и функции коммуникации.

Согласно М. Хэллидею, язык отвечает на три вида социально-функциональных потребностей человека: во-первых, уметь понимать и интерпретировать то, что происходит внутри и вокруг нас; во-вторых, взаимодействовать с реальным миром путём согласования социальных ролей и отношений; в-третьих, уметь создавать смыслы с точки зрения того, что является данным и новым (тема-рематические отношения). Эти функции языка М. Хэллидей называет метафункциями и обозначает их как идеаторную, межличностную и текстовую, соответственно; использование языка задействует все три метафункции одновременно [14].

Ещё одним важным и фундаментальным понятием системно-функциональной лингвистики является понятие выбора. Парадигматические отношения считаются первичными и образующими смысловой потенциал языка путём систематизации основных компонентов во взаимосвязанных системах характеристик. Поэтому одной из основных задач SFL является определение возможных вариантов создания этого смыслового потенциала в реальных контекстах и ситуациях через ресурсы, доступные для выражения в языке. Синтагматические отношения рассматриваются как реализация системы в контексте определённого высказывания (дискурсе), что обусловливает формальные и структурные последствия выбора конкретной функции языка. М. Хэллидей подчёркивает важность понятия выбора, поскольку текст представляет собой «непрерывный процесс семантического выбора. Текст - это значение, а значение - это выбор» [там же, с. 137]. Поэтому язык скорее следует рассматривать как обмен значениями в межличностных контекстах, а функционирование языка - как осмысленный выбор, а не набор формальных правил. Как видим, системно-функциональная теория принимает парадигматическую ось в качестве отправной точки в понимании того, как функционирует язык.

Начало развития собственно функциональной лингвосинергетики было положено Евгенией Витальевной Пономаренко и продолжено в трудах А.А. Харьковской, Д.С. Храмченко, В.Л. Малаховой, И.В. Савиной, А.В. Радюк и других. Среди основных принципов функциональной лингвосинергетики выделяются следующие:

- анализ самоорганизационных процессов языка и дискурса в тесной взаимосвязи, причём самоорганизация понимается как мобилизация функционально-смыслового потенциала всех компонентов текста,

- нелинейность языка и дискурса на фоне нелинейности их внешней среды (истории и коллективного сознания этноса, сознания конкретных коммуникантов и параметров коммуникативной ситуации),

- активное взаимодействие языка и дискурса с внешней средой,

- определяющий характер параметров порядка по отношению к функционированию элементов системы языка и дискурса,

- направленность элементов к аттрактору (коммуникативной цели),

- проявление процессов оптимизации и информационного сжатия в виде тенденции английского языка и дискурса к экономии [7]; [8]; [16].

Ещё одной особенностью SFL и функциональной лингвосинергетики является тесная связь с прагматикой. Это обусловливает важность интерпретации смысла в зависимости от определённого дискурсивного пространства. Иными словами, функциональная лингвосинергетика анализирует, каким образом тот или иной смысл, представляющий собой прагма-семантическое целое, формируется языковыми средствами в определённом контексте, какие дополнительные факторы 
воздействуют на этот процесс. При этом дискурс-анализ прежде всего учитывает коммуникативную ситуацию - погружение языкового пространства в реальность, что определяет коммуникативное использование языка, описание языковых фактов в аспекте человеческой деятельности, отношения между знаком и теми, кто его использует, с акцентом на функции знака. Это способствует поиску коммуникативных параметров языка, обеспечивая не абстрактный обмен информацией, а реальный процесс общения, складывающийся из множества компонентов, которые включают информативный контент и влияют на участников коммуникации и их действия.

Конечной целью использования языка является не просто создание или знание «правильных» лингвистических структур/форм, но формирование желаемого смыслового пространства и решение определённых коммуникативных задач. Поэтому для функциональной лингвосинергетики важна функциональность языка, поскольку без функции структура превращается в малосодержательную схему [12]. Тем не менее, чтобы эффективно активизировать и анализировать функции языка, необходимо понимать, как он структурирован. Таким образом, системные функционалисты воспринимают язык как социальную семиотическую систему, в которой его значение и форма всегда определяются контекстом, параметрами ситуации и коммуникативными целями участников общения.

Функциональная лингвосинергетика использует различные виды анализа, включая анализ выражения, содержания и контекста. Контекст вносит первостепенный вклад в процесс формирования смысла. Человек говорит и пишет не изолированными предложениями, а значимыми единицами - текстами, которые создаются в пространстве определённого дискурса и подвержены его влиянию.

\section{3. Заключение}

Хотя синергетика считается довольно новым этапом в развитии теории систем с особым акцентом на вопросы эволюции и фазовых сдвигов, будучи междисциплинарной по своему характеру, она объединяет множество наук, имеющих дело с открытыми, динамичными, самоорганизующимися сложными системами, развивающимися нелинейно в различных средах. Междисциплинарность синергетики заключается в синтезе методов исследования, разработанных и внедрённых в естественных науках.

Лингвосинергетика, или лингвистическая синергетика, представляет собой такой междисциплинарный исследовательский подход к изучению языка. Применение синергетических принципов в исследовании языка является не только возможным, но и необходимым, поскольку язык соответствует всем критериям синергийной системы - является открытой, динамической, нелинейной, самоорганизующейся системой с множеством иерархических подсистем и элементов, которые взаимосвязаны и функционируют под действием регулирующих параметров порядка. Это сложная синергийная мегасистема, которая изменяется и развивается в соответствии с универсальными принципами поведения сложной системы, раскрытыми в теории синергетики. Потенциал лингвосинергетики открывает границы для всесторонних исследований языка как синергийной системы и позволяет расширить наше понимание природы, функционирования и перспектив развития языка.

Поскольку структура и организация языка обусловливают его функции на всех уровнях, представляется закономерным появление системной функциональной лингвосинергетики как направления, изучающего организацию функциональной структуры. Язык является источником смысла во многих и постоянно меняющихся контекстах человеческого взаимодействия; особенность языка заключается в его организации как огромной сети взаимосвязанных выборов.

Функциональная лингвосинергетика рассматривает язык как систему систем с потенциалом смысла, с помощью которого его пользователи передают значение, делая выбор из целого ряда альтернатив языковых средств. При этом формирование общего смыслового пространства произведения речи происходит по принципу нелинейности $(2+2=5)$, так как общий смысл, как правило, превосходит механическую сумму смыслов отдельных компонентов текста.

(C) Малахова В.Л., 2021 


\section{Список литературы}

1. Базылев В.Н. Синергетика языка: Овнешнение в гадательных практиках / В.Н. Базылев. М.: Диалог - МГУ, 1998.180 с.

2. Березин Ф.М. О парадигмах в истории языкознания XX в. / Ф.М. Березин // Лингвистические исследования в конце XX в.: Сб. обзоров (Сер.: «Теория и история языкознания») / исслед. Отдел языкознания, Редколл.: Березин Ф.М., отв. ред. и др. М., 2000. С. 9-25.

3. Князева Е.Н. Основания синергетики: Синергетическое мировидение / Е.Н. Князева, С.П. Курдюмов. М.: Книжный дом «ЛИБРО-КОМ», 2010. 256 с.

4. Майнцер К. Сложносистемное мышление: Материя, разум, человечество. Новый синтез. Пер. с англ. / К. Майнцер / Под ред. и с предисл. Г.Г. Малинецкого. М.: Книжный дом «ЛИБРОКОМ», 2009. 464 с.

5. Мандельброт Б. Фрактальная геометрия природы / Б. Мандельброт. М.: Институт компьютерных исследований, 2002. $656 \mathrm{c}$.

6. Миронова Ю.В. Художественный дискурс как когнитивный диалог о «языке - доме духа» / Ю.В. Миронова, Т.И. Сокольская // Дискурспрофессиональной коммуникации. № 3(2). 2021. С. 33-42. DOI: https://doi.org/10.24833/26870126-2021-3-2-33-42

7. Пономаренко Е.В. Системность функциональных связей в современном английском дискурсе: Автореферат дис. ... доктора филологических наук / Е.В. Пономаренко. Москва, 2004. 47 с.

8. Пономаренко Е.В. Функциональная системность дискурса и предпосылки развития лингвосинергетики / Е.В. Пономаренко // Вестник Российского университета дружбы народов. Серия: Лингвистика. 2006. № 2. С. 22-27.

9. Пономаренко Е.В. Нелинейность как системное свойство функционального пространства английского делового дискурса / Е.В. Пономаренко, Г.А. Паршутина // Вестник Самарского университета. История, педагогика, филология. 2018. T. 24. № 3. C. 156-160. DOI: https://doi.org/10.18287/2542-0445-2018-24-3-156-160

10. Bishop R.C. Metaphysical and epistemological issues in complex systems / R.C. Bishop // Philosophy of Complex Systems. Handbook of the Philosophy of Science / Ed. by C. Hooker. Amsterdam: Elsevier, 2011. Vol. 10. P. 105-136.

11. Coffman J.A. On causality in nonlinear complex systems: The developmentalist perspective / J.A. Coffman // Philosophy of Complex Systems. Handbook of the Philosophy of Science / Ed. by C. Hooker. Amsterdam: Elsevier, 2011. Vol. 10. P. 287-309.

12. Fontaine L. Analysing English grammar: A systemic functional introduction / L. Fontaine. Cambridge: Cambridge University Press, 2012. $294 \mathrm{p}$.

13. Haken H. Information and self-organization: A macroscopic approach to complex systems. 2nd enlarged edition / H. Haken. Berlin: Springer, 2000. 222 p.

14. Halliday M.A.K. Language as social semiotic / M.A.K. Halliday. London: Edward Arnold, 1978. 256 p.

15. Khramchenko D.S. Functional-linguistic parameters of English professional discourse // Professional Discourse \& Communication. 2019. № 1(1). P. 9-20. DOI: https://doi.org/10.24833/2687-0126-2019-1-1-9-20

16. Khramchenko D.S. Planning the functional field of business English discourse: Linguosynergetic approach // Вопросы прикладной лингвистики. 2015. № 18. С. 151-163.

17. The American heritage science dictionary [Электронный ресурс]. URL: http://www.dictionary.com/browse/attractor (дата доступа 10.06.2021).

\section{References}

1. Bazylev, V.N. Sinergetika iazyka: Ovneshnenie v gadatel'nykh praktikakh [Synergetics of language: Outwardness in fortunetelling practices]. Moscow: Dialogue - Moscow State University, 1998. 180 p. (In Russian).

2. Berezin, F.M. O paradigmakh $\mathrm{v}$ istorii iazykoznaniia XX v. [On paradigms in the history of linguistics of the $20^{\text {th }}$ century] // Lingvisticheskie issledovaniia $v$ kontse XX v.: Sb. obzorov (Ser.: "Teoriia i istoriia iazykoznaniia") [Linguistic studies at the end of the twentieth century: Reviews (Series "Theory and history of linguistics")]. Moscow, 2000. P. 9-25 (In Russian).

3. Knyazeva, E.N., Kurdyumov S.P., Osnovaniia sinergetiki: Sinergeticheskoe mirovidenie [Foundations of synergetics: Synergetic worldview]. Moscow: LIBRO-KOM, 2010. 256 p. (In Russian).

4. Mainzer, K. Slozhnosistemnoe myshlenie: Materiia, razum, chelovechestvo. Novy sintez. Per. s angl. [Complex system thinking: Matter, mind, humanity. New synthesis. Translated from English] / Ed. by G.G. Malinetskiy. Moscow: LIBRO-KOM, 2009. 464 p. (In Russian).

5. Mandelbrot, B. Fraktal'naia geometriia prirody [Fractal geometry of nature]. Moscow: Institute for Computer Research, 2002. 656 p. (In Russian).

6. Mironova, Y.V., Sokolskaya, T.I. Literary discourse as a cognitive dialogue about «Language as the house of spirit» // Professional Discourse \& Communication. No. 3(2). P. 33-42. (In Russian). DOI: https://doi.org/10.24833/2687-0126-2021-3-2-33-42.

7. Ponomarenko, E.V. Sistemnost' funktsional'nykh sviazei v sovremennom angliiskom diskurse [Systemacy of functional links in modern English discourse]. Doctor's Thesis Abstract. Moscow, 2004. 47 p. (In Russian).

8. Ponomarenko, E.V. Funktsional'naia sistemnost' diskursa i predposylki razvitiia lingvosinergetiki [Functional systemity of discourse and prerequisites for development of linguosynergetics] // Vestnik Rossiyskogo universiteta druzhby narodov. Seriia: Lingvistika [Bulletin of the Peoples' Friendship University of Russia. Series: Linguistics]. 2006. No. 2. P. $22-27$ (In Russian).

9. Ponomarenko, E.V., Parshutina G., Nelineinost' kak sistemnoe svoistvo funktsional'nogo prostranstva angliyskogo delovogo diskursa [Non-linearity as systemic property of functional space of Business English discourse] // Vestnik of Samara University. History, pedagogics, philology. 2018. Vol. 24. No. 3. P. 156-160. (In Russian). DOI: https://doi.org/10.18287/2542-0445-201824-3-156-160 
10. Bishop, R.C. Metaphysical and epistemological issues in complex systems // Philosophy of complex systems. Handbook of the philosophy of science / Ed. by C. Hooker. Amsterdam: Elsevier, 2011. Vol. 10. P. 105-136.

11. Coffman, J.A. On causality in nonlinear complex systems: The developmentalist perspective // Philosophy of complex systems. Handbook of the philosophy of science / Ed. by C. Hooker. Amsterdam: Elsevier, 2011. Vol. 10. P. 287-309.

12. Fontaine, L. Analysing English grammar: A systemic functional. Cambridge: Cambridge University Press, 2012. 294 p.

13. Haken, H. Information and self-organization: A macroscopic approach to complex systems. $2^{\text {nd }}$ enlarged edition. Berlin: Springer, 2000. 222 p.

14. Halliday, M.A.K. Language as social semiotic. London: Edward Arnold, 1978. 256 p.

15. Khramchenko, D.S. Functional-linguistic parameters of English professional discourse // Professional Discourse \& Communication. 2019. No. 1 (1). P. 9-20. DOI: https://doi.org/10.24833/2687-0126-2019-1-1-9-20.

16. Khramchenko, D.S. Planning the functional field of business English discourse: Linguosynergetic approach // Voprosy prikladnoi lingvistiki [Applied linguistics issues]. 2015. No 18. C. 151-163.

17. The American heritage science dictionary, http://www.dictionary.com/browse/attractor (date of access 10.06.2021).

\section{Сведения об авторе:}

Малахова Виктория Леонидовна - кандидат филологических наук, доцент, доцент кафедры английского языка № 4 МГИМО. Сфера научных интересов: функциональная лингвосинергетика, дискурс-анализ, категория притяжательности, функциональные свойства, когнитивная лингвистика, фразеологически передаваемый концепт, межкультурная коммуникация.

E-mailv.l.malakhova@inno.mgimo.ru

\section{About the author:}

V.L. Malakhova - PhD (Philology), Associate Professor, Assistant Professor of English Language Department № 4, MGIMO University (Russia, Moscow). Research interests: functional linguosynergetics, discourse, possession, cognitive linguistics, phraseologically represented concept, intercultural communication.

E-mailv.l.malakhova@inno.mgimo.ru 